\title{
Espaço aberto à divulgação de livros doados à Biblioteca do CEM
}

Serão divulgados apenas os livros que se enquadram nos critérios de catalogação da Biblioteca do CEM, especializada em migrações.

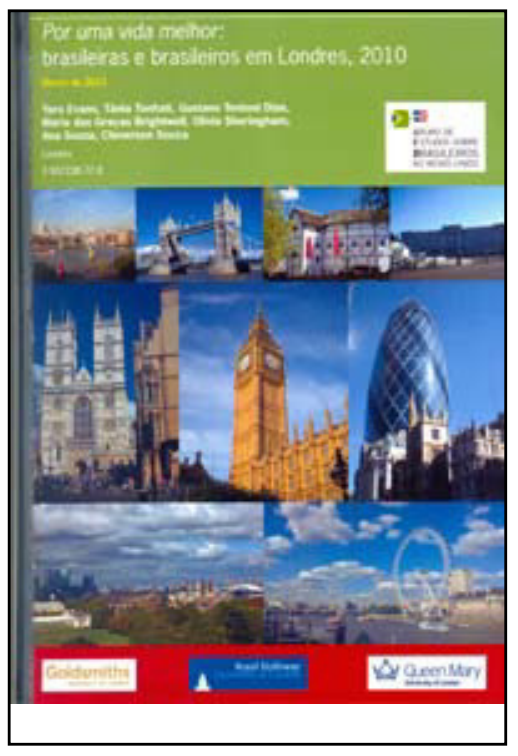

O GEB-Grupo de Estudos sobre Brasileiros no Reino Unido, entre junho e setembro de 2010, realizou um levantamento por amostragem dos brasileiros/as residentes em Londres, cujos resultados encontram-se nesta publicação. Foram recolhidos 553 questionários, sendo $53 \%$ impressos e $47 \%$ em formato eletrônico. Com base nos dados obtidos foi traçado um perfil dos imigrantes brasileiros considerando: faixa etária, gênero, nível de instrução, situação imigratória, tempo de residência em Londres, inserção no mercado de trabalho, local de residência, entre outros. Vale destacar que além da publicação impressa, é possivel acessar os dados no website: http://gold.ac.uk/ clcl/geb/ ou no blog: http://geblondon.wordpress.com/ nas versões português e inglês.

O livro analisa as fronteiras demográficas, econômicas, políticas e culturais dos brasiguaios na região leste do Paraguai. A imigração brasileira neste país gera fronteiras simbólicas, hibridismos culturais, variadas tensões e experiências diversas de circulação econômica, de pessoas e símbolos. Tanto assim que os limites fixos dos mapas das nações não correspondem à dinâmica da vida nos espaços fronteiriços.

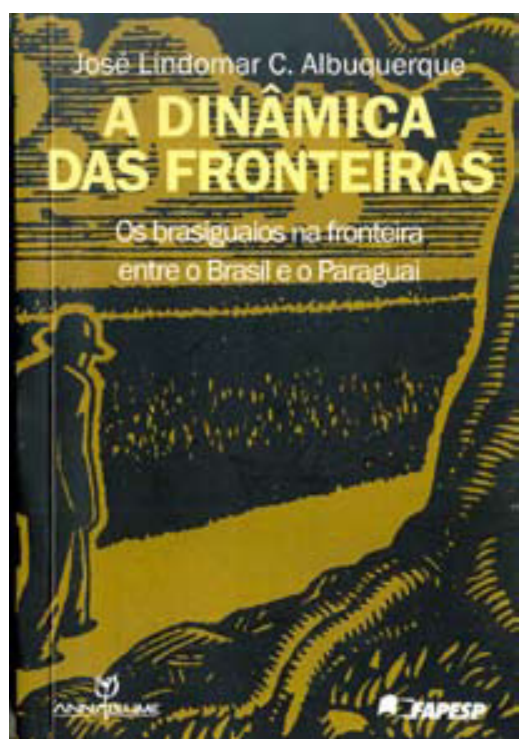




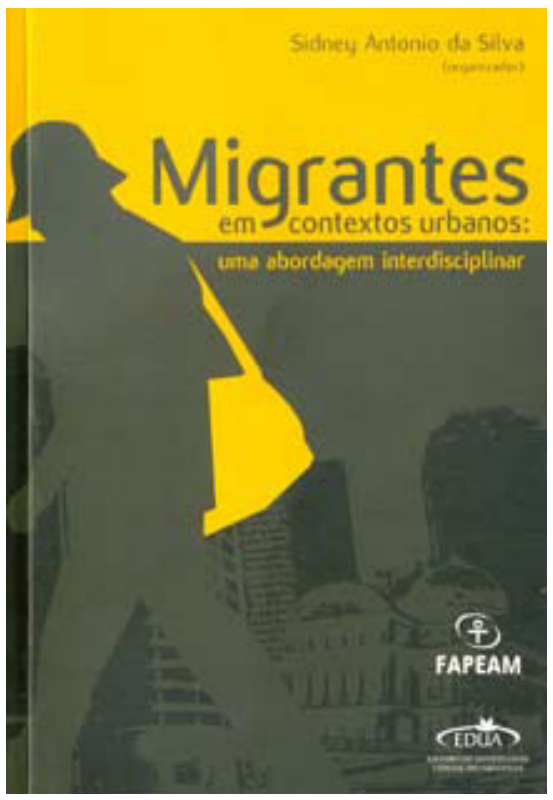

O livro é resultado do Seminário "Migrações na Amazônia: desafios e perspectivas", organizado em novembro de 2008 pelo GEMA - Grupo de Estudos Migratórios na Amazônia. A maior parte dos textos volta-se para a realidade migratória envolvendo a cidade de Manaus (migrantes internos, indígenas, peruanos, refugiados colombianos), mas há os que tratam de Rondônia, do Nordeste, de maranhenses, além de outros, entre os quais, o texto que abre o livro, voltado para uma compreensão teórica da mobilidade do trabalho.

Milhares de pessoas do movimento dekassegui retornaram ao Brasil, sobretudo após a crise de 2008. O Projeto Kaeru volta-se para os filhos envolvidos nesse processo, os quais são definidos no Japão como "Double limited", ou seja, não aprenderam nem japonês, nem português. Ao retornarem, enfrentam sérios problemas de aprendizagem e de integração social. Por isso, o Projeto destina-se a oferecer apoio psicológico, social, psicopedagógico, alfabetização e reforço escolar às crianças do ensino fundamental da rede pública de educação do Estado de São Paulo. Pelo caráter desta publicação - um relatório - também encontramos um balanço dos atendimentos realizados e a indicação de desafios que ainda persistem.

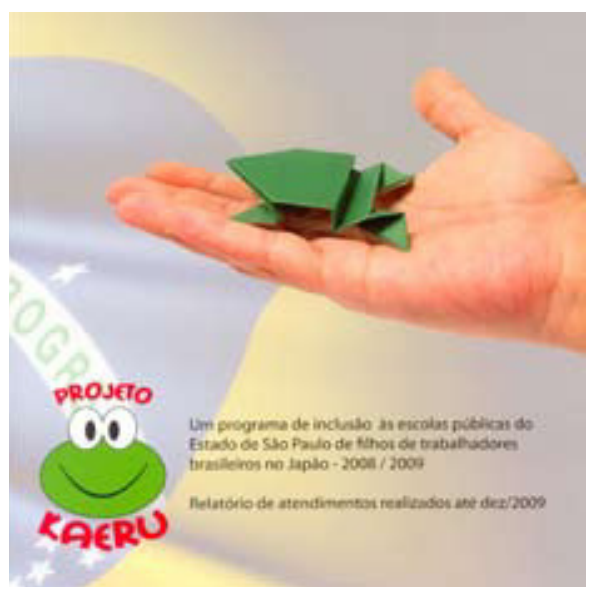




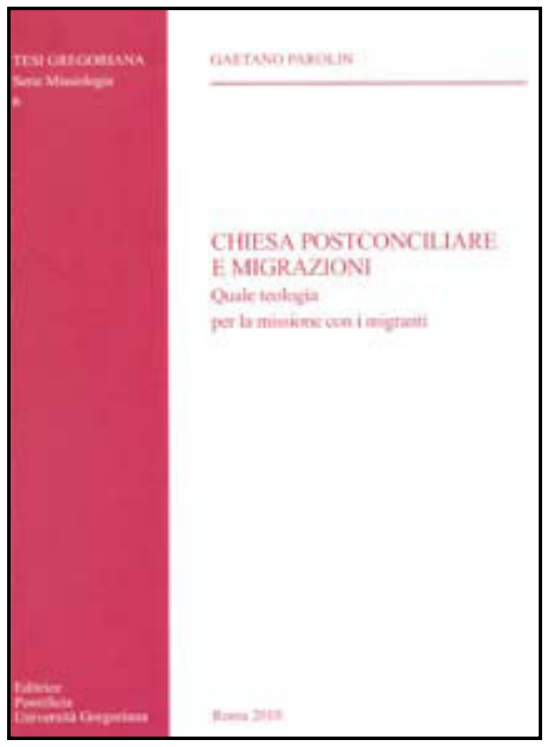

Ao todo, o livro traz 16 artigos, que podem ser agrupados sob 5 aspectos: a) A história urbana do país e o processo de redistribuição espacial da população; b) As transformações na dinâmica do crescimento da população, cidades, metrópoles e aglomerados e suas condições de vida; c) A configuração atual das cidades, com destaque para a segregação socioespacial, qualidade de vida e cidadania, gestão urbana e habitação; d) A melhoria na qualidade da informação e indicadores para a gestão pública, políticas e ações; e) Os processos migratórios, tanto em relação ao último fio do êxodo rural, como em relação às tendências mais recentes: migração de retorno e internacionais.
Partindo do momento histórico presente em que as migrações constituem um fenômeno de época, este estudo, resultado de tese em missiologia, traz uma leitura interdisciplinar da realidade migratória, buscando evidenciar os significativos nexos que resultam do diálogo entre as ciências humanas e as teológicas. 0 caráter processual e relacional das migrações, a dimensão inacabada das identidades nacionais, étnicas e culturais oferecem à teologia a possibilidade de contar com um espaço hermenêutico que permite falar ao mesmo tempo de Deus, da pessoa humana, do mundo, de Cristo e da Igreja. A análise da profunda relação existente entre missão e migração permite lançar a hipótese de que a missão para, com e entre os migrantes se constitui num novo paradigma da missão em si da Igreja.

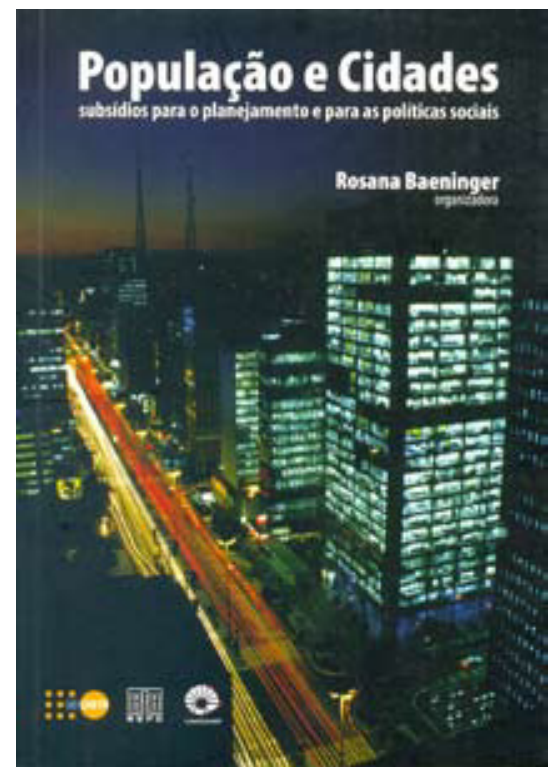

